\title{
LEITURA COMO AÇÃO COLETIVA DE COMPETÊNCIA NA PRODUÇÃO DE RESULTADO SIGNIFICATIVO
}

\author{
'Vilma Conceição da silva \\ ${ }^{2}$ Orientador: Prof. Dr. Márcio Wendel S. Coêlho
}

\begin{abstract}
RESUMO
O objetivo do trabalho é de buscar configurar a leitura na ação coletiva enquanto processo de resultado significativo nas condições determinadas humana que são traçados condições, em que o social é agente contribuidor e delimitador do discurso em seu âmbito de produção individual ou coletivo o desenvolvimento das teorias sobre a leitura acompanha o desenvolvimento da própria linguística. Em uma retrospectiva histórica na pesquisa dessa habilidade, três elementos se alternam como focos de atenção: o autor o leitor $\mathrm{e} o$ texto. A ênfase em um e outro estar diretamente relacionada às diferentes concepções de linguagem, que terminam por modular as várias práticas e orientações em sala de aula. É inegável que a leitura do texto escrito constitui uma conquista da humanidade. Pela leitura, o ser humano não só absorve o conhecimento, como pode transformá-lo em um processo de aperfeiçoamento continuo. A aprendizagem da leitura possibilita a emancipação da criança e a assimilação dos valores da sociedade. É na família que a criança forma a sua identidade e desenvolve o seu equilíbrio emocional. Uma das missões dos pais é a transmissão de valores éticos e morais, os pais que oferece às crianças, desde cedo o contato com obras-primas de literatura, infantil, ou seja, tomar contato com os livros de boa qualidade. Com isso, é possível que a criança crie o hábito e o prazer pela leitura, sendo uma atividade prazerosa entre os filhos e seus familiares construindo uma forma mágica de brincar com as palavras, estimulando as crianças a desenvolver o gosto pela leitura.
\end{abstract}

Palavras chaves: leitura, ação coletiva, escola, resultado significativo.

\begin{abstract}
The objective of the work is to seek to configure reading in collective action as a process of significant result in determined human conditions, in which the social is a contributing and delimiting agent of discourse in its scope of individual or collective production, the development of theories about reading accompanies the development of linguistics itself. In a historical retrospective in the research of this skill, three elements alternate as focuses of attention: the author, the reader and the text. The emphasis on one and the other is directly related to the different conceptions of language, which end up modulating the various

\footnotetext{
${ }^{1}$ Vilma Conceição da silva mestre em ciências da educação.Email:

vilmahagatinha@gmail.com

${ }^{2}$ Orientador: Prof. Dr. Márcio Wendel S. Coêlho. Email: mwdoctormaster@gmail.com
} 
practices and orientations in the classroom. It is undeniable that the reading of the written text constitutes an achievement of humanity. By reading, the human being not only absorbs knowledge, but can transform it into a process of continuous improvement. Learning to read enables the child's emancipation and the assimilation of society's values. It is in the family that the child forms his identity and develops his emotional balance. One of the parents' missions is the transmission of ethical and moral values, the parents who offer children, from an early age, contact with masterpieces of literature, for children, that is, make contact with good quality books. With this, it is possible for the child to create the habit and the pleasure of reading, being a pleasurable activity among the children and their families, building a magical way of playing with words, encouraging children to develop a taste for reading.

Key words: reading, collective action, school, significant result.

\section{RESUMEN}

El objetivo del trabajo es buscar configurar la lectura en la acción colectiva como un proceso de resultado significativo en determinadas condiciones humanas, en el que lo social es un agente del discurso contribuyente y delimitador en su ámbito de producción individual o colectiva al desarrollo de teorías sobre la lectura acompaña el desarrollo de la lingüística en sí. En una retrospectiva histórica en la investigación de esta habilidad, se alternan tres elementos como focos de atención: el autor, el lector y el texto. El énfasis en uno y otro está directamente relacionado con las distintas concepciones del lenguaje, que acaban modulando las distintas prácticas y orientaciones en el aula. Es innegable que la lectura del texto escrito constituye un logro de la humanidad. Al leer, el ser humano no solo absorbe conocimientos, sino que puede transformarlos en un proceso de mejora continua. Aprender a leer permite la emancipación del niño y la asimilación de los valores de la sociedad. Es en la familia donde el niño forma su identidad y desarrolla su equilibrio emocional. Una de las misiones de los padres es la transmisión de valores éticos y morales, los padres que ofrecen a los niños, desde temprana edad, el contacto con obras maestras de la literatura, para los niños, es decir, el contacto con libros de buena calidad. Con esto, es posible que el niño cree el hábito y el placer de la lectura, siendo una actividad placentera entre los niños y sus familias, construyendo una forma mágica de jugar con las palabras, animando a los niños a desarrollar el gusto por la lectura.

Palabras clave: lectura, acción colectiva, escuela, resultado significativo. 


\section{INTRODUÇÃO}

\section{Concepção da leitura}

Esse significado consiste em um levantamento sobre leitura, para Solé (2008, p.22) "é um processo de interação entre o leitor e o texto". É um momento único em que o leitor deve examinar detalhadamente o texto, identificando as ideias principais, a mensagem que o autor quer passar.

Nesse processo, "não quer dizer que o significado que o escrito tem para o leitor não é uma réplica do significado que o autor quis lhe dar, mas uma construção que envolve o texto, os conhecimentos prévios do leitor que 0 aborda e seus objetivos." (SOLÉ, 1998, p.22).

Nesse breve histórico da leitura e escrita é, um recurso na formação social e cultural, a leitura é um componente de referência essencial para o ingresso e a participação na sociedade letrada. Portanto, é uma ferramenta básica da comunicação do homem contemporâneo e a chave do saber que possibilita a participação ativa do cidadão na civilização moderna com perfeito domínio de símbolos e sinais significantes.

\section{MÉTODOS}

Com base nos estudos, este artigo de revisão bibliográfica, que apresenta principais discussões e pesquisas em, bem como estratégias de leitura como ação coletiva de competência na produção de resultado significativo embasado na concepção de alguns autores. Dessa forma acredita-se o ato de ler é revolucionário, pois transforma o leitor passivo em leitor ativo, um co-autor, doador de sentimentos e, além de capacitá-lo para o estudo e uso de obra literária, capacita-o a influencias do contexto histórico e, entender, interelacionar com questões referentes à sociedade de determinada época, as independentemente do tempo, da obra a analisar situações ainda existentes no contexto educativo.

\section{ANÁLISE E DISCUSSÃO}


Para isso, a pesquisa aqui desenvolvida possui caráter bibliográfico com uma abordagem qualitativa, tendo contado a pesquisa de campo para melhor entendimento tantos dos elementos que compõem as novas necessidades de aprendizagem, como do papel que a formação docente representa na busca da melhoria da qualidade no processo de leitura da criança. Sendo o educador o fio condutor de interesses e fazeres na educação.

Sabe-se, conforme Freire (2003, p. 04), que é praticando a leitura que se aprende ser um bom leitor, já que "Se é praticando que se aprende a nadar, Se é praticando que se aprende a trabalhar, É praticando também que se aprende a ler e a escrever. Vamos praticar para entender e aprender para praticar melhor".

É então apresentado na primeira temática os fundamentos e construções históricas acerca da formação docente, conceituando e situando sua importância no que se refere a construção de conhecimentos e habilidades inovadoras, que dão ao profissional subsídios para atuarem de forma a suprir a novas exigências educacionais, sociais e tecnológicas da educação, visto que a excelência na qualidade educativa está intimamente entrelaçada com o fazer docente, sendo seu preparo fundamental no processo de leitura e seus novos propósitos e vias.

$\mathrm{Na}$ seguinte, abordo o olhar de Magda Soares acerca da reconstrução da atividade de alfabetização que deu vida ao tão conhecido Letramento, enquanto ação que não apenas se codifica o código escrito, mas se atrela a essa codificação significados da vida real, onde a leitura assume papel reflexivo e social acerca da realidade de quem lê.

É necessário que a escola busque delinear as características e funções desses elementos na constituição da leitura e do processo de apropriação e desenvolvimento do conhecimento, capazes de eleger leituras e mecanismos discursivos mais adequadas aos objetivos individuais e coletivos da instituição, e acima de tudo, dos indivíduos em seu contexto.

O sucesso no processo de aprendizagem escolar depende de alguns elementos considerados fundamentais: a organização do espaço físico como: uma boa sala de leitura, a disponibilidade de materiais educacionais, além do envolvimento no processo de desenvolvimento dos filhos. A aprendizagem envolve pensamento, afeto, linguagem e ação. Esses processos precisam estar 
em harmonia para que o sucesso seja obtido, e a família tem o papel essencial e indispensável nesse processo.

O bom leitor não se faz por acaso. Muitos são formados na infância, em família que podem lhes oferecer contato com a literatura infantil e em escolas que proporcionam experiências positivas no início da alfabetização (CARVALHO, 2010, p. 11).

Então, crianças que seus pais leem diariamente e se mostram dedicados pelos livros têm muito mais chance de se interessarem por a leitura. Os pais devem dar o exemplo, se gostam de ler, se estão sempre com um livro na mão, a criança também vai querer fazer isso, comprar livros, promover rodas de leitura com os filhos, eventos de conversas, contar histórias, lendas, piadas essas são formas culturais que também ajudam muito, pois despertam a curiosidade e incentivam a intimidade da criança com os livros. "Ninguém nasce sabendo ler, aprende-se a ler à medida que se vive. Se ler livros geralmente se aprende nos bancos da escola, outras leituras se aprendem por aí, na chamada escola da vida [...]." (LAJOLO, 2005, p.07).

Notando-se importância da escola para o incentivo à leitura assim a educação institucional não se faz sozinha, busco na última temática ressaltar a importância da relação escola-família no compartilhando interesses na/da aprendizagem das crianças do Ensino Fundamental, isso inclui o estímulo e produção de significados e contextos propícios ao desenvolvimento da leitura.

De acordo Alarcão (2004, p. 12) "as escolas são lugares onde as novas competências devem ser adquiridas ou reconhecidas e desenvolvidas". É no espaço escolar que a prática da leitura se faz presente na vida das pessoas desde o momento em que passam a compreender o mundo a sua volta. No constante desejo de aprender a ler, de interpretar o sentido das coisas que os cercam, de perceber o mundo sob diversas maneiras, de relacionar a ficção com a realidade em que vivem no contato com um livro, enfim, em toda essa situação, está de certa forma lendo, embora muitas vezes o indivíduo não se dê conta disso. O educando adquiri habilidades para falar, escrever, ler e interpretar textos orais e escritos em situações mais cotidianas ou mais formais.

Segundo os Parâmetros Curriculares Nacionais (1997, p. 54): 
Um leitor competente só pode constituir-se mediante uma prática constante de leitura de textos de fato, a partir de um trabalho que deve se organizar em torno da diversidade de textos que circulam socialmente. Esse trabalho pode envolver todos os alunos, inclusive aqueles que ainda não sabem ler convencionalmente.

Quando ler, é para aprender a ter interação com a prática da língua portuguesa e com todas as áreas do conhecimento. A prática de leitura deve acontecer no espaço escolar buscando um âmbito completo em que o educando tenha a necessidade e a vontade de se relacionar com o que está escrito. É importante que o educando entenda que ler é uma interação e absorção de um mundo, por isso deve existir diversidade de textos para que o educando possa escolher o mais apropriado ao seu gosto e a sua realidade, só assim poderá reduzir os problemas na aquisição da leitura. De acordo Soares (2010, p. 60):

\footnotetext{
É importante que o aluno conviva com vários gêneros textuais, para que entre em contato com diferentes usos sociais da língua e perceba por que e para que se utiliza a escrita. Essa vivência vai possibilitar o conhecimento de diversos textos e vai ajudá-lo a interagir com diferentes modelos. Além disso, essa interação possibilitará ao aluno se manifestar de uma forma variada ao produzir os textos.
}

O educador precisa buscar variedades de textos para diversificar sua aula, assim o educando vai aprendendo mais e seu potencial avançará, nem só na leitura quanto em sua escrita, oralidade nas produções textuais e também para seu desempenho enquanto pessoa na sociedade em que vive.

\section{CONSIDERAÇÕES FINAIS}

Acredita-se que, na formação competente, é necessário exercitar as desenvolturas de leituras no intuito de desenvolver as competências comunicativas com essências de valores, condutas e sensibilidades por parte dos leitores. Sabe-se, a leitura é fundamental no processo ensinoaprendizagem para participar de uma cultura mais sofisticada na sociedade, 
apresentada simbolicamente através dos desejos e utopia do leitor. Para isso, escola/família/educador possuem papéis distintos, colaborativos e integrados que conduzem o desenvolvimento da leitura como premissa para a produção de um leitor dentro da integralidade de relações e saberes que a contemporaneidade requer na busca de cada sujeito em suprir suas carências e atingir seus anseios.

E vale a pena argumentar que para se realizar um trabalho significativo com a leitura o qual possa resultar em um leitor crítico, é preciso se desprender de atividades de reprodução que visam tão somente fazer o aluno-leitor passar os olhos sobre o texto, decodificando as palavras e se prendendo a superficialidade do escrito e oralidade através de da temática. Portanto, formar o leitor críticos e autônomos é uma necessidade de se construir cidadãos também críticos, para lutarem por seus espaços na sociedade e no mercado de trabalho, sendo investigativo reflexivo, realizando seus ofícios com eficiência.

O papel da educação antes de tudo oferece todos os instrumentos de crítica e reflexão acerca da sociedade em que vivemos, enfim, de que possamos superar a continuidade de tradições, pois ela supõe a possibilidade de rupturas, pela qual a cultura se renova e o homem se aperfeiçoa construindo sua nova história.

Sendo de competência do educador o desenvolvimento de estratégias pedagógicas que viabilizem o estreitamento. É fundamental que escola crie projetos de leitura, busque também sala de leitura ou bibliotecas, jogos que envolvem leituras entre a família e a escola e o resgate das relações e responsabilidades sobre o desenvolvimento educacional da criança, sendo a prática docente um dos elos dessa relação fundamental ao fazer educativo e à formação social da criança.

Buscando assim compreender a relevância da formação docente na busca em suprir as novas necessidades educacionais da leitura, tais como o letramento, - multiletramento e a relação escola-família enquanto fator essencial ao estímulo, desenvolvimento, produção de significados e da identidade que dá ao sujeito melhores contextos naquilo que se aprende e apreende através do ato da leitura.

O educador em particular tem uma responsabilidade extraordinária na formação e no aperfeiçoamento da pessoa como ser integral. O educador 
constrói e deve estar comprometido com as pessoas, não somente com o conhecimento, mas com o bom uso desses conhecimentos que servirão como luz para iluminar e alimentar toda a existência. Ser educador é ter percepção, impulso vital para a sobrevivência, trabalhar o desconhecido que mora dentro de cada educando, de modo que se possa evoluir nesta grande Teia da Vida.

\section{REFERÊNCIAS BIBLIOGRÁFICAS}

ALARCÃO, Isabel. Professores reflexivos em uma escola reflexiva - 3. Ed. São Paulo, Cortez, 2004, - (Coleção da Nossa Época; 103).

BRASIL. Secretaria de Educação Fundamental. Parâmetros curriculares nacionais: língua portuguesa. Brasília: MEC/SEF, 1997.

CARVALHO, Marlene. Guia prático do alfabetizador. - 1. Ed. - São Paulo: ática, 2010. 11 p. - (Princípios)

FREIRE, Paulo. A importância do ato de ler: em três artigos que se completam. - 45. Ed. - São Paulo, Cortez, 2003.

LAJOLO, Marisa. Do Mundo da leitura para a leitura do mundo. 6. ed. São Paulo, Ática, 2005.109p.

SILVA, Ezequiel Theodoro. $\mathbf{O}$ ato de ler: fundamentos psicológicos para uma nova pedagogia da leitura. $5^{\underline{a}}$ ed. São Paulo: Cortez: Autores Associados, 1991.

SOARES, Magda. Novas práticas de leitura e escrita: letramento na cibercultura. Educ. Soc., Campinas, vol. 23, n. 81, p. 143-160, dez. 2002. Acesso: 29 de novembro, 2014. Disponível em: http://www.scielo.br/pdf/es/v23n81/13935

SOARES, Maria Inês Bizzotto. Alfabetização Linguística: da teoria à prática. - Belo Horizonte: Dimensão, 2010. 60p.

SOLÉ, Isabel. Estratégias de leitura. 6. ed. Porto Alegre: Artmed, 1998. 